Check for updates

Cite this: RSC Adv., 2017, 7, 22063

\title{
Regeneration of dental-pulp complex-like tissue using phytic acid derived bioactive glasses $\uparrow$
}

\author{
Cai-Yun Cui, ${ }^{\text {ab }}$ Sai-Nan Wang, ${ }^{\text {ab }}$ Hui-Hui Ren, ${ }^{c}$ Ai-Ling Li, ${ }^{c}$ Dong Qiu, ${ }^{c}$ Ye-Hua Gan ${ }^{\text {bbd }}$ \\ and Yan-Mei Dong (D) *ab
}

Phytic acid derived bioactive calcium phosphosilicate (PSC) glasses with a high phosphate content were synthesised by using non-toxic phytic acid as a phosphorus precursor. This study aimed to verify the effects of PSC on the odontogenic differentiation and dentin-pulp complex-like tissue regeneration of dental pulp cells (DPCs). Nitrogen adsorption, field-emission scanning electron microscopy, Fourier transform infrared spectroscopy, $\mathrm{pH}$ measurement, and inductively coupled plasma optical emission spectroscopy analyses were performed to characterise PSC. Classical 45S5 bioactive glasses (45S5) were used as positive control. Cell proliferation (1, 3, 5, 7 and 9 days), odontogenic-related gene expression levels ( 3 and 7 days) and mineralisation ability (21 days) of human DPCs (hDPCs) were evaluated with methylthiazol tetrazolium assay, real-time polymerase chain reaction and alizarin red staining after hDPCs from third molars were treated with PSC or 45S5 extractions. Rat molar crowns with pulp tissues covered by PSC or $45 S 5$ were transplanted subcutaneously into nude mice for 2 and 6 weeks to demonstrate their biological effects in vivo. Results revealed that the specific surface area of PSC was larger than that of 45S5. The PSC also induced hydroxycarbonate apatite precipitation earlier than 45S5. pH was slightly increased when the amount and dissolution time of PSCs were increased. By comparison, $\mathrm{pH}$ was remarkably increased by $45 \mathrm{~S} 5$. The amounts of $\mathrm{Si}$ and $\mathrm{P}$ ions released by $\mathrm{PSC}\left(0.1 \mathrm{mg} \mathrm{mL} \mathrm{m}^{-1}\right)$ were larger than those released by $45 \mathrm{~S} 5$. Cell proliferation, mRNA expression levels of dentin sialophosphoprotein, dentin matrix protein 1 and osteocalcin and mineralisation of hDPCs were also more strongly promoted by PSC than by 45S5. In vivo, the amount of induced typical dentin-like tissues with odontoblast-like cells generated on the interface between materials and pulp tissues was higher in PSC than in 45S5. Only collagen-like tissues were observed in groups without bioactive glasses. These findings suggested that PSC enhanced the odontogenic differentiation of DPCs and dentin-pulp complex-like tissue regeneration. The PSC might be a potential candidate for vital pulp preservation and regeneration of the dentin-pulp complex.

Received 5th February 2017

Accepted 7th April 2017

DOI: $10.1039 / \mathrm{c} 7 \mathrm{ra01480e}$

rsc.li/rsc-advances have been synthesized and used as promising materials in bone and dental hard tissue regeneration. ${ }^{1}$ Although BGs for dentin regeneration have been rarely examined, other BGs, including calcium phosphosilicate BGs, have been reported. For example, the ionic dissolutions of $45 \mathrm{~S} 5$ and $58 \mathrm{~S},{ }^{2} \mathrm{BG}$ particles alone or BG particles with scaffolds, such as collagen, gelation and poly caprolactone,$^{3-6}$ promote the odontogenic differentiation and mineralisation of human dental pulp cells (hDPCs) in vitro. $58 \mathrm{~S}$ particles induce dentin-pulp complex formation after heterotopic transplantation in vivo. ${ }^{7} 45 \mathrm{~S} 5$ as a pulp capping agent in mini swine molars induces the formation of a reparative dentin bridge. ${ }^{\mathbf{8} 9}$ However, acute inflammation or pulp tissue necrosis caused by $45 \mathrm{~S} 5$ for tissue regeneration has yet to be evaluated. ${ }^{\mathbf{8 , 1 0}}$ BGs also require 1 to 2 years before they disappear from the body; consequently, the long-term effect of silica and the slow degradation of BGs have caused another problem. ${ }^{\mathbf{1 1}}$ Therefore, new compositions of BGs should be developed to improve their processability, bioactivity and biodegradability for dentin-pulp complex regeneration.
${ }^{a}$ Department of Cariology and Endodontology, Peking University School and Hospital of Stomatology, 22 Zhongguancun Avenue South, Haidian District, Beijing 100081, P. R. China. E-mail: kqdongyanmei@bjmu.edu.cn; Fax: +86-10-62173402; Tel: +86-10 82195475

nal Engineering Laboratory for Digital and Material Technology of Stom Beijing Key Laboratory of Digital Stomatology, 22 Zhongguancun Avenue South Haidian District, Beijing 100081, P. R. China

${ }^{c}$ Beijing National Laboratory for Molecular Sciences, State Key Laboratory of Polymer Physics and Chemistry, Institute of Chemistry, Chinese Academy of Sciences, 2 Beijing Zhongguancun North Street, Haidian District, Beijing 100190, P. R. China

${ }^{d}$ Central Laboratory, Peking University School and Hospital of Stomatology, 22 Zhongguancun Avenue South, Haidian District, Beijing 100081, P. R. China. E-mail: kqyehuagan@bjmu.edu.cn; Fax: +86-10-82193402; Tel: +86-10-82195518

$\dagger$ Electronic supplementary information (ESI) available. See DOI: 10.1039/c7ra01480e 
Phytic acid derived bioactive calcium phosphosilicate glasses (PSC) are synthesized with phytic acid (inositol hexakisphosphate, IP6) as a phosphorus precursor to increase its phosphate content to $22.7 \mathrm{wt} \% .^{12}$ Phosphate in BGs separates into a phosphate rich bilayer and promotes hydroxycarbonate apatite (HCA) formation because of the bioactive properties of BGs. ${ }^{1}$ Phosphate materials exhibit good biocompatibility and bioresorbability, and changes in the phosphate content in BGs affect the bioactivity and degradation rates varying from hours to several weeks. ${ }^{11}$ PSC is also bioactive at high phosphate contents with a reduced onset temperature of calcinations, and its structural characteristics resemble those of calcium phosphates in physiological media. ${ }^{13}$ Therefore, the bioactive properties of PSC are different from those of other BGs with different phosphorus precursors. ${ }^{14}$

This study aimed to verify the effects of PSC on the odontogenic differentiation of DPCs in vitro and dentin formation in vivo for dentin-pulp complex regeneration.

\section{Materials and methods}

\section{PSC preparation}

Traditional melt 45S5 ( $45 \mathrm{wt} \% \mathrm{SiO}_{2}, 24.5 \mathrm{wt} \% \mathrm{CaO}, 6 \mathrm{wt} \% \mathrm{P}_{2} \mathrm{O}_{5}$ and $\left.24.5 \mathrm{wt} \% \mathrm{Na}_{2} \mathrm{O}\right)$ and the sol-gel PSC (48.2 wt $\% \mathrm{SiO}_{2}, 29.1$ $\mathrm{wt} \% \mathrm{CaO}$ and $22.7 \mathrm{wt} \% \mathrm{P}_{2} \mathrm{O}_{5}$ ) were used. PSC was prepared in accordance with previously described methods. ${ }^{12}$ Phytic acid is a naturally derived compound, and its chemical structure is illustrated in Fig. 1. In brief, phytic acid was firstly mixed with ethanol and water. Tetraethylorthosilicate (Sinopharm Chemical Reagent Co., Ltd.) and $\mathrm{Ca}\left(\mathrm{NO}_{3}\right)_{2} \cdot 4 \mathrm{H}_{2} \mathrm{O}$ (Sinopharm Chemical Reagent Co., Ltd.) were added to form sols. The sols were sealed and allowed to gel. The resultant gels were aged at ambient temperature for 2 days and dried at $60{ }^{\circ} \mathrm{C}$ for 1 week and at $120^{\circ} \mathrm{C}$ for another 2 weeks. The dried gels were heated to $400{ }^{\circ} \mathrm{C}$ and exposed to this temperature for $1 \mathrm{~h}$ to produce solgel PSC.

\section{Characterisation of PSC particles}

The particle size distributions of PSC were evaluated by using an LA-950 laser particle size analyzer (Horiba, Japan). The specific

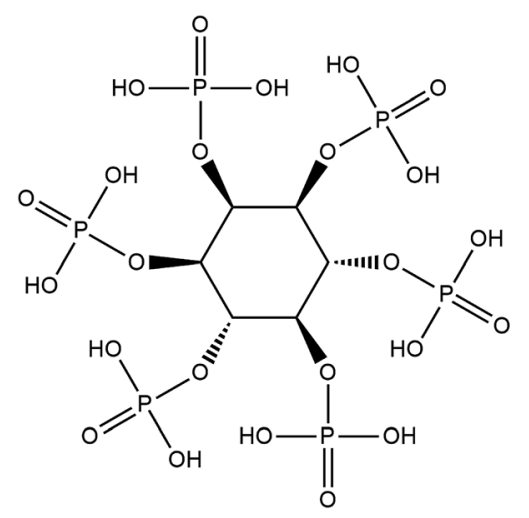

Fig. 1 The molecular structure of phytic acid. surface area of the PSC particles was measured through $\mathrm{N}_{2}$ adsorption at $77.35 \mathrm{~K}$ (Nova 4200e, Quantachrome, USA). The specific surface area of the particles was calculated on the basis of a Brunauer-Emmett-Teller plot of an adsorption-desorption isotherm by using adsorption points in the $P / P_{0}$ range from 0.05-0.35 (NOVA Win software, Quantachrome, USA).

\section{Apatite-forming ability of PSC in a simulated body fluid (SBF)}

PSC and $45 \mathrm{~S} 5\left(0.1 \mathrm{mg} \mathrm{mL}^{-1}\right)$ were separately immersed in SBF $\left(\mathrm{Na}^{+} 142, \mathrm{~K}^{+} 5.0, \mathrm{Mg}^{2+} 1.5, \mathrm{Ca}^{2+} 2.5, \mathrm{Cl}^{-} 147.8, \mathrm{HCO}^{3-} 1.0\right.$ and $\left.\mathrm{SO}_{4}{ }^{2-} 0.5 \mathrm{mmol} \mathrm{L}^{-1}\right)^{15}$ for 12,24 and $72 \mathrm{~h}$. The solids were collected and characterised through field-emission scanning electron microscopy (FE-SEM, S4800, JEOL, Japan) and Fourier transform infrared spectroscopy (FTIR, Nexus, USA).

\section{pH and ion concentration of PSC extractions}

PSC and 45S5 extractions were prepared in accordance with a previously described method. ${ }^{2}$ In brief, PSC and 45 S5 were separately incubated in Dulbecco's Modified Eagle Medium (DMEM, Gibco, Gaithersburg, MD) at concentrations of 0.01 , $0.1,1,2,4$ and $8 \mathrm{mg} \mathrm{mL}^{-1}$ for $24 \mathrm{~h}$ and at $0.1,1 \mathrm{mg} \mathrm{mL}^{-1}$ for 1,3 , 6,12 and $24 \mathrm{~h}$ at $37^{\circ} \mathrm{C}$. The incubated samples were centrifuged at $14000 \mathrm{~g} \mathrm{~min}^{-1}$ for $10 \mathrm{~min}$, and the supernatants were collected and filtered through a $0.22 \mu \mathrm{m}$ filter (Millipore, Billerica, MA). The $\mathrm{pH}$ of the extractions was determined by using a pH meter (pHS-3C pH Automation, China).

The $\mathrm{Si}, \mathrm{Ca}$ and $\mathrm{P}$ concentrations in the PSC and $45 \mathrm{~S} 5$ extractions $\left(0.1 \mathrm{mg} \mathrm{mL}^{-1}, 24 \mathrm{~h}\right)$ were detected through inductively coupled plasma optical emission spectroscopy analysis (ICAP 6300, Thermo Electron Corporation, Waltham, MA). DMEM was set as the control group.

PSC extraction $\left(0.1 \mathrm{mg} \mathrm{mL}^{-1}\right)$, 45S5 extractions $(0.1 \mathrm{mg}$ $\mathrm{mL}^{-1}$ ) and DMEM supplemented with $10 \mathrm{v} / \mathrm{v} \%$ foetal bovine serum (FBS, Hyclone, Logan, UT), $2 \mathrm{mmol} \mathrm{L}^{-1} \mathrm{~L}$-glutamine and $100 \mathrm{U} \mathrm{mL}^{-1}$ penicillin-streptomycin (Gibco, Gaithersburg, MD) were used for cell culture in the following experiments.

\section{Cell proliferation assay}

hDPCs were isolated from impacted third molars of patients aged 19-25 years with patients' consent and ethical approval (PKUSSIRB-2013014) and in accordance with previously described methods. ${ }^{7,16}$ In brief, hDPCs were seeded into a 96well plate $\left(5 \times 10^{3}\right.$ cells per well $)$ and cultured overnight. The culture medium was replaced with PSC extraction, 45S5 extraction or DMEM. Methylthiazol tetrazolium (MTT) assay (Sigma, USA) was used to determine the viability of hDPCs at 1 , 3, 5, 7 and $9 \mathrm{~d}$. The optical density (OD) at $490 \mathrm{~nm}$ of the samples was determined using an ELx808 absorbance microplate reader (BioTeK Instruments, Winooski, VT).

\section{Odontogenic-related gene expression of hDPCs by real-time PCR}

hDPCs were seeded into a 6-well plate $\left(5 \times 10^{3}\right.$ per $\left.\mathrm{cm}^{2}\right)$ and the culture medium was replaced with PSC extraction, $45 \mathrm{~S} 5$ extraction or DMEM when the cells reached $80-90 \%$ 
confluence. After 3 and $7 \mathrm{~d}$, the total RNA of hDPCs was extracted, reverse-transcribed and subjected to real-time PCR. ${ }^{7}$ The primers set for real-time PCR are shown in Table 1.

\section{Mineralisation ability assay by alizarin red staining}

The PSC and $45 \mathrm{~S} 5$ particles $\left(0.1 \mathrm{mg} \mathrm{mL}^{-1}\right)$ coating on a 24 -well plate were prepared as previously described. ${ }^{7}$ The hDPCs $(5 \times$ $10^{3}$ per $\mathrm{cm}^{2}$ ) were seeded into a coated plate and the culture medium was changed into DMEM with osteo/dentinogenic medium (OM) as previously described when the cells reached 80-90\% confluence. ${ }^{17}$ The cells cultured in DMEM were used as the negative control group. After $14 \mathrm{~d}$, the cells were fixed and incubated in alizarin red (0.1 wt\%, $30 \mathrm{~min}$ ) (Sigma, USA). Alizarin red was destained with cetylpyridinium chloride (100 $\mathrm{mmol} \mathrm{L}^{-1}, 30 \mathrm{~min}$ ) (Sigma, USA) and the OD of the samples at $562 \mathrm{~nm}$ was determined.

\section{Effects of PSC on dental pulp tissue in vivo}

The animal experiments were approved by the Animal Use and Care Committee of Peking University (LA2011-057) and the ARRIVE Guidelines checklist of this report was included in the ESI file. $\dagger$ The experiments were conducted as previously described. ${ }^{7}$ Thirty-eight first molars were obtained from 4 week old Sprague-Dawley rats, and the teeth were cut into the crown and root parts at the tooth neck. All of the crowns were randomly divided into three groups: crowns covered with PSC powder $(n=14), 45 \mathrm{~S} 5$ powder $(n=14)$ on the cross-section of the coronal pulp and crowns alone as the control $(n=10)$. All of the samples were randomly transplanted subcutaneously into nude mice. After 2 and 6 weeks, the samples were retrieved, fixed, decalcified (10 wt\% EDTA) and embedded in paraffin. The sections $(5 \mu \mathrm{m})$ were histologically analysed with haematoxylin-eosin staining (HE) and Masson's trichrome (Baso Diagnostic Inc., China) staining according to the manufacturer's recommendation.

Histological results were evaluated by two observers who were blinded in terms of groupings. Each sample was evaluated on the basis of the scores of the extent of dental pulp necrosis and hard tissue formation according to the criteria described in previous studies. ${ }^{18,19}$ The standards of scoring are listed in Table 2: 1 indicates the highest result and 4 denotes the lowest result.
Table 2 Samples with the PSC transplanted in vivo ${ }^{a}$

\begin{tabular}{|c|c|c|c|c|c|c|}
\hline \multirow{2}{*}{$\begin{array}{l}\text { Observation } \\
\text { period }\end{array}$} & \multirow[b]{2}{*}{ Numbers of samples } & \multicolumn{5}{|c|}{$\begin{array}{l}\text { Grading of the histologic } \\
\text { sections }^{b}\end{array}$} \\
\hline & & 1 & 2 & 3 & 4 & Mean score \\
\hline \multicolumn{7}{|l|}{2 weeks } \\
\hline CTR & 5 & 0 & 0 & 5 & 0 & 3 \\
\hline $45 \mathrm{~S} 5$ & 7 & 3 & 0 & 0 & 4 & 2.71 \\
\hline PSC & 7 & 5 & 0 & 0 & 2 & 1.86 \\
\hline \multicolumn{7}{|l|}{6 weeks } \\
\hline CTR & 5 & 0 & 0 & 5 & 0 & 3 \\
\hline $45 \mathrm{~S} 5$ & 7 & 5 & 0 & 0 & 2 & 1.86 \\
\hline PSC & 7 & 6 & 0 & 0 & 1 & 1.43 \\
\hline \multicolumn{7}{|c|}{$\begin{array}{l}a \text { Means for each group in each sub item of the criteria: } 1=\text { highest } \\
\text { result and } 4=\text { lowest result. }{ }^{b} \text { Score of } 1 \text { : samples with hard tissue } \\
\text { deposition and without pulp tissue necrosis; } 2: \text { samples with hard } \\
\text { tissue deposition and pulp tissue necrosis; } 3: \text { samples without hard } \\
\text { tissue deposition and pulp tissue necrosis; } 4: \text { samples without hard } \\
\text { tissue deposition and with pulp tissue necrosis. }\end{array}$} \\
\hline
\end{tabular}

\section{Statistical analysis}

Data were expressed as mean \pm standard deviation (SD) and assessed through one-way ANOVA or Mann-Whitney $U$ test. Statistical significance was analysed with SPSS 19.0. $P<0.05$ was considered statistically significant.

\section{Results}

\section{Characterisation of PSC}

As revealed by the LA-950 laser particle size analyser (Horiba, Japan), the average particle diameters of PSC (Fig. 2b) and $45 \mathrm{~S} 5$ (Fig. 2a) were $21 \pm 12$ and $15 \pm 11 \mu \mathrm{m}$, respectively. The specific surface areas of PSC and $45 \mathrm{~S} 5$ verified by $\mathrm{N}_{2}$ adsorption experiments were 53.5 and $1.2 \mathrm{~m}^{2} \mathrm{~g}^{-1}$, respectively. The average particle diameter of PSC was larger than that of 45S5, and the specific surface area of the former was larger than that of the latter mainly because of the possible contribution of pores formed during the sol-gel process.

\section{Apatite-forming ability of PSC in SBF}

FE-SEM images reveal the surfaces of PSC and 45S5 were smooth and did not possess apatite precipitates before they

Table 1 Oligonucleotide primer sequences

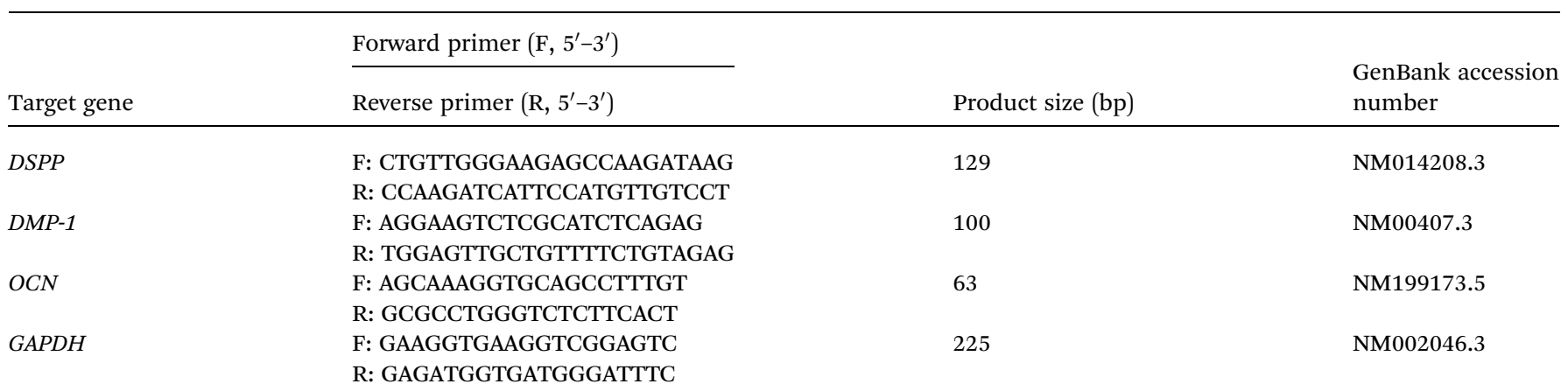



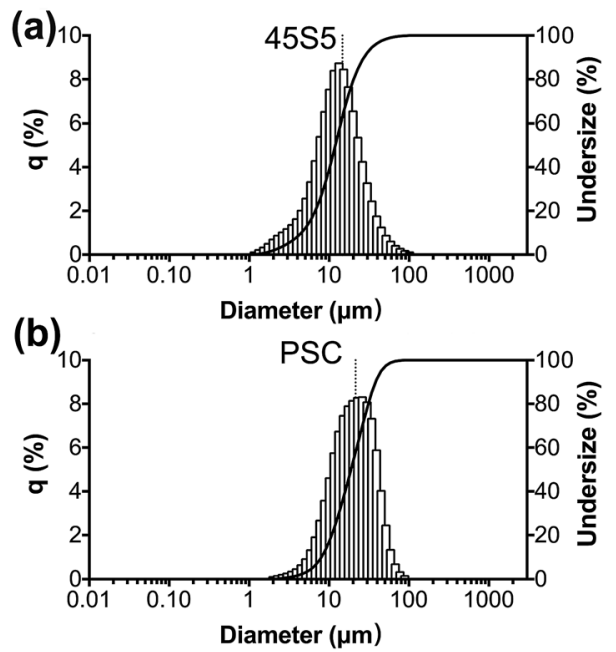

Fig. 2 Characterization of the PSC. (a) Particle size distributions of $45 \mathrm{~S} 5$ by LA-950 laser particle size analyzer. (b) Particle size distributions of PSC.

were soaked in SBF (Fig. 3a and e). The surfaces became coarser and partially covered by mineral precipitates at $12 \mathrm{~h}$ soaking in SBF (Fig. 3b and f). The precipitates gradually grew with a flower-like layer and covered the whole surfaces at 24 and $72 \mathrm{~h}$ soaking in SBF (Fig. 3c, d, g and h).

FTIR results showed that the characteristic absorption bands of Si-O-Si bonding were at 1060 and $480 \mathrm{~cm}^{-1}$ before they were soaked in SBF (Fig. 3i and j). However, a double peak near 562 and $603 \mathrm{~cm}^{-1}$ corresponding to the $\mathrm{P}-\mathrm{O}$ bending vibrations of the phosphate groups in a crystalline environment appeared at $12 \mathrm{~h}$ soaking in SBF. This phenomenon indicated the formation of hydroxyapatite (HA) minerals. This absorption band of phosphate groups became more intense as the duration of soaking in SBF was prolonged. Therefore, the HA layer continuously grew at 24 and $72 \mathrm{~h}$. Nevertheless, the intensities of the double peak in PSC were generally greater than those in 45S5 at 12 and $24 \mathrm{~h}$. The weak $\mathrm{C}-\mathrm{O}$ vibration of the phosphate groups near 869 $\mathrm{cm}^{-1}$ implied the initial presence of sodium hydrogen carbonate at $72 \mathrm{~h}$.

\section{$\mathrm{pH}$ and ion concentration of PSC extractions}

Fig. 4a illustrates that the $\mathrm{pH}$ of PSC and 45S5 extractions dosedependently increased from $0.01 \mathrm{mg} \mathrm{mL}^{-1}$ to $8 \mathrm{mg} \mathrm{mL}^{-1}$ after they were incubated for $24 \mathrm{~h}$. The $\mathrm{pH}$ of $45 \mathrm{~S} 5$ extractions significantly increased from 7.66 to 8.84 , whereas the $\mathrm{pH}$ of PSC extractions only increased slightly from 7.63 to 7.98. After incubation for $24 \mathrm{~h}$, the $\mathrm{pH}$ of $45 \mathrm{~S} 5$ extractions $\left(1 \mathrm{mg} \mathrm{mL} \mathrm{m}^{-1}\right)$ rapidly increased from 7.45 to 8.11 during the first $1 \mathrm{~h}$ and then reached the platform (Fig. $4 \mathrm{~b}$ ). The $\mathrm{pH}$ of $45 \mathrm{~S} 5$ extractions (0.1 $\left.\mathrm{mg} \mathrm{mL}^{-1}\right)$ and PSC extractions (0.1 and $1 \mathrm{mg} \mathrm{mL}^{-1}$ ) remained below 7.70, 7.65 and 7.74, respectively (Fig. 4b).

The ICP results revealed that the ion concentrations of Si and $\mathrm{P}$ in the PSC extractions were higher than those in 45S5 $0.1 \mathrm{mg}$ $\mathrm{mL}^{-1}, 24 \mathrm{~h}$ ) (Fig. 4c).
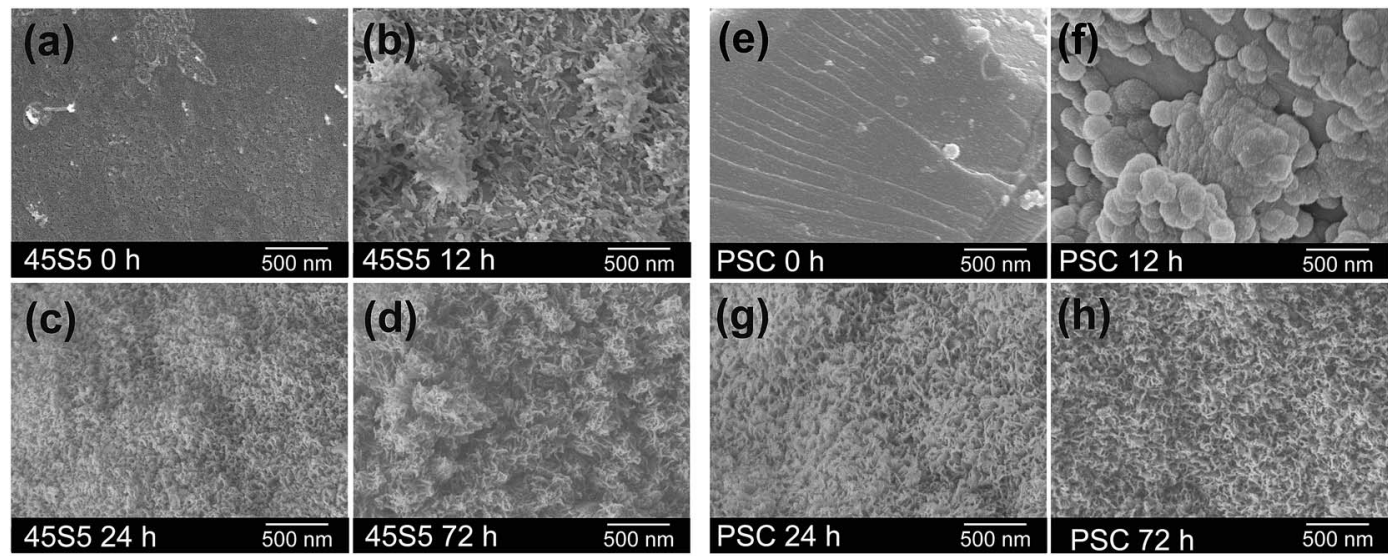

(i)

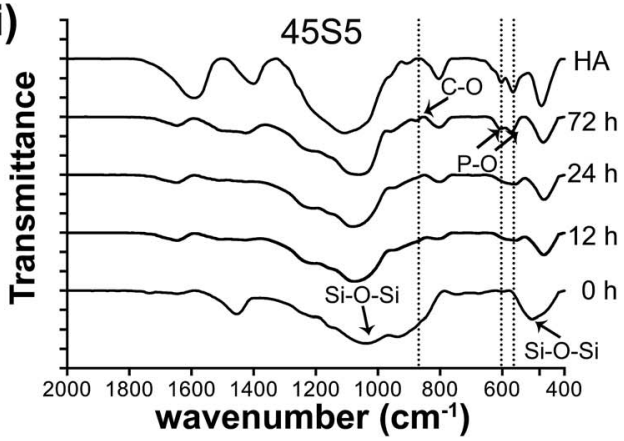

(j)

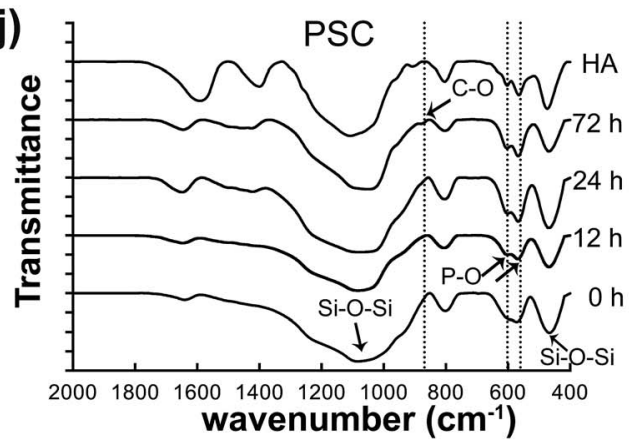

Fig. 3 Apatite-forming ability of PSC in SBF. (a-h) The FE-SEM results showed the representative morphologies of the 45 S5 and PSC after soaking in SBF for 0, 12, 24 and $72 \mathrm{~h}$. ( $\mathrm{i}$ and j) The FTIR results showed spectra of the 45S5 and PSC before and after soaking in SBF for 12,24 and $72 \mathrm{~h}$. 


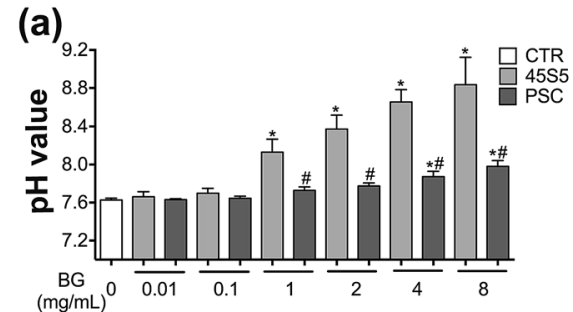

(b)

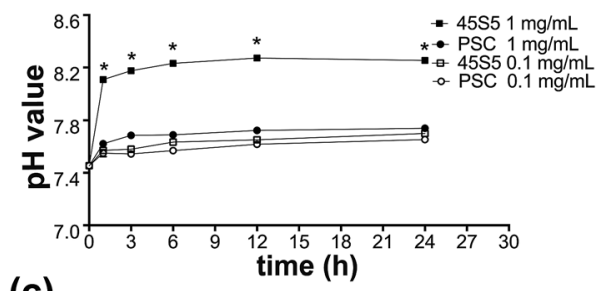

(c)

Table. Concentrations of $\mathrm{Si}, \mathrm{Ca}$, and $\mathrm{P}$ in the $45 \mathrm{~S} 5$ and PSC extractions (DMEM, $0.1 \mathrm{mg} / \mathrm{mL}, 24 \mathrm{~h}$ )

\begin{tabular}{cccc}
\hline & $\mathrm{Si}(\mathrm{ppm})$ & $\mathrm{Ca}(\mathrm{ppm})$ & $\mathrm{P}(\mathrm{ppm})$ \\
\hline DMEM & $0.70 \pm 0.23$ & $72.12 \pm 1.85$ & $28.64 \pm 0.94$ \\
$45 S 5$ & $13.96 \pm 0.65^{\star}$ & $73.16 \pm 1.59$ & $27.78 \pm 2.66$ \\
PSC & $19.43 \pm 0.33^{* \#}$ & $74.22 \pm 2.07$ & $31.59 \pm 3.76^{\#}$ \\
\hline
\end{tabular}

Fig. $4 \mathrm{pH}$ and ions concentration of extractions of PSC. (a) The $\mathrm{pH}$ value assay results showed changes of $\mathrm{pH}$ in different $\mathrm{BG}$ concentrations after incubation for $24 \mathrm{~h}(* p<0.05$ vs. CTR, $\# p<0.05$ vs. $45 \mathrm{~S} 5$ in the same concentration) and (b) changes at different time point in 0.1 and $1 \mathrm{mg} \mathrm{mL}^{-1}\left({ }^{*} p<0.05 \mathrm{vs}\right.$. PSC in the same concentration). (c) The ICP results showed the ionic concentrations of $\mathrm{Si}, \mathrm{Ca}$, and $\mathrm{P}$ in the $45 \mathrm{~S} 5$ and PSC extractions ( $* p<0.05$ vs. CTR, \#p $<0.05$ vs. 45S5). CTR, control.

\section{Effects of PSC on hDPCs in vitro}

The proliferation rates of the cells treated with PSC and 45S5 extractions were higher than those of the control group from day 5 to day 9 (Fig. 5). The proliferation rates of the cells in the PSC group were also higher than those in the 45S5 group from day 5 to day 9.

Compared with that of the control group, the mRNA expression levels of $D S P P$ and $D M P-1$ were significantly upregulated in the PSC group from day 3 to day 7 (Fig. 6). Their expression levels were significantly upregulated only on day 7 in the 45S5 group. Their expression was higher in the PSC group

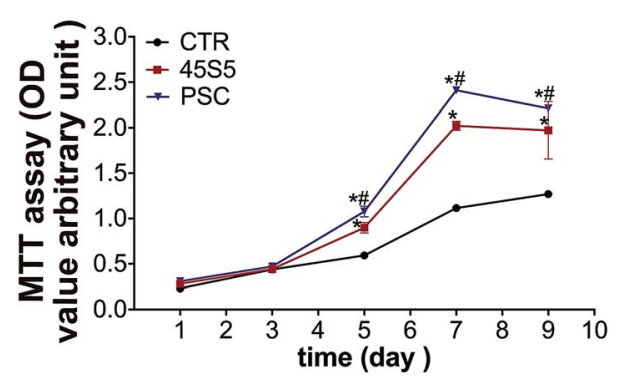

Fig. 5 PSC promoted cell proliferation of hDPCs in vitro. MTT assay results showed the effects of PSC and 45S5 on the cell proliferation of hDPCs ( $* p<0.05$ vs. CTR, $\# p<0.05$ vs. $45 S 5, n=3$ ).
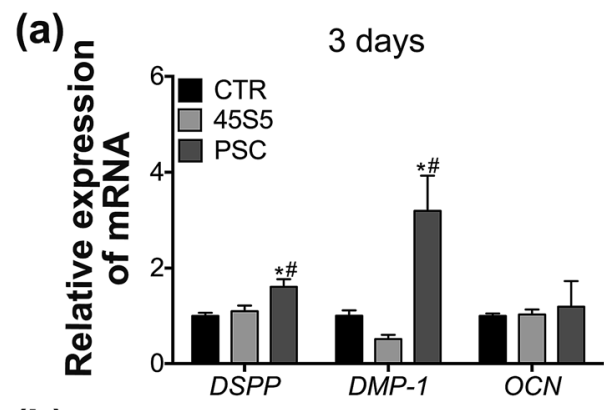

(b)

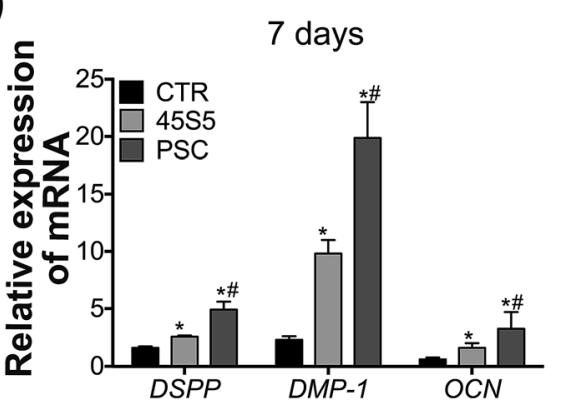

Fig. 6 PSC promoted odontogenic differentiation of hDPCs in vitro. (a and $b)$ The $\mathrm{QPCR}$ results showed the mRNA expression of DSPP, DMP1 and OCN of hDPCs cultured in extractions of $45 S 5$ and PSC for 3 and 7 days $(* p<0.05$ vs. CTR, $\# p<0.05$ vs. $45 S 5, n=3$ ).

than that in the $45 \mathrm{~S} 5$ group from day 3 till day 7 . The mRNA expression of $O C N$ were significantly up-regulated only on day 7 in the PSC group and 45S5 compared with that of the control group, whereas its expression in the PSC group was also higher than that in the $45 \mathrm{~S} 5$ group on day 7 .

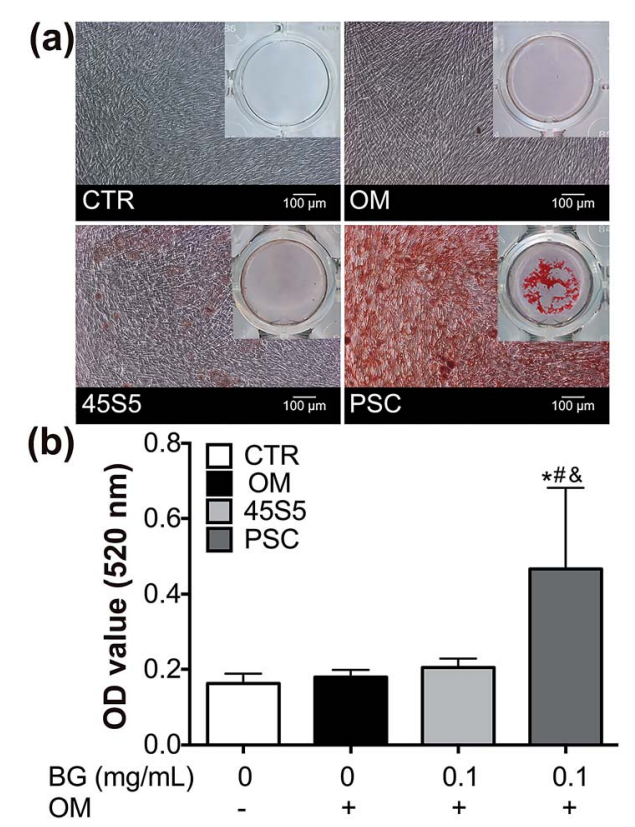

Fig. 7 PSC promoted mineralization of hDPCs in vitro. (a and b) The alizarin red staining assay results showed generation of mineralized nodules of hDPCs cultured with 4555 or PSC particles for 14 days ( ${ }^{*} p<$ 0.05 vs. CTR, $\# p<0.05$ vs. OM, \&p< 0.05 vs. $45 S 5, n=3$ ). OM, osteo/ dentinogenic medium; CTR, control. 
In Fig. 7a, red staining was observed in the PSC group, 45S5 group and OM but not in the control group on day 14. Red staining was also evident in hDPCs treated with PSC particles. In Fig. $7 b$, the density of the red mineralised nodules was higher in the PSC group than in the other groups. No statistical difference was found in the 45S5 group, OM and the control group.

\section{Effects of PSC on dental pulp tissue in vivo}

Considering dental pulp necrosis and hard tissue formation, we observed that the scores of PSC $(1.86,1.43)$ were lower than those of 45S5 $(2.71,1.86)$ at 2 and 6 weeks (Table 2). Fig. 8 shows that collagen-like tissue was generated at the cross-section of the crowns in the control group at 2 and 6 weeks (Fig. 8a-d). A new layer of reactive-dentin formed below the primary dentin at 6 weeks (Fig. 8c). 45S5 and PSC stimulated the generation of dental pulp-dentin complex-like tissue at the cross-section at 2 and 6 weeks (Fig. 8e-1). In the PSC group, the mineralised matrix was generated on the PSC surface in contact with the pulp tissue (Fig. 8f and h). A regular tubule-like structure was also detected in the newly generated matrix at 2 weeks (Fig. 8j and $\mathrm{j}^{\prime}$ ), and the dentin-like tissue continuously generated and thickened at 6 weeks (Fig. $8 \mathrm{l}$ and $\mathrm{l}^{\prime}$ ). Polarising odontoblast-like cells appeared along this new dentin layer at 2 weeks (Fig. $8 \mathrm{j}$ and $\mathrm{j}^{\prime}$ ), but the phenomenon was not found at 6 weeks (Fig. 81 and $\mathrm{l}^{\prime}$ ). A new layer of reactive dentin was also produced below the primary dentin at 6 weeks (Fig. 8h). The same phenomenon was observed in the $45 \mathrm{~S} 5$ group (Fig. 8e and g). However, the structures of the tubule- and dentin-like tissue and the polarising odontoblast-like cells were not as typical as those in the PSC group (Fig. 8i, i', $\mathrm{k}$ and $\mathrm{k}^{\prime}$ ). The layer of dentin-like tissue was also thinner than that in the PSC group at 6 weeks (Fig. $8 \mathrm{~g}$ and $\mathrm{h}$ ).

\section{Discussion}

This study described novel BGs called PSC with superior biocompatibility for dental pulp cells and ability to regenerate
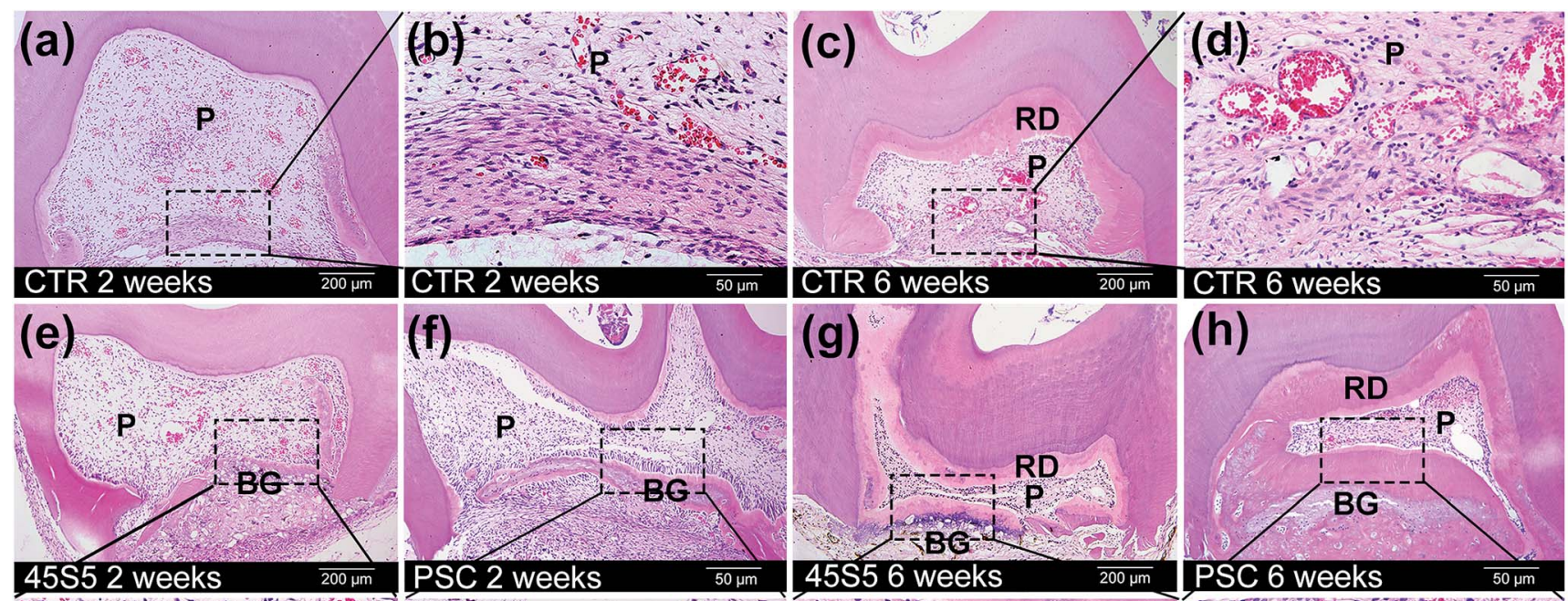

CTR 6 weeks

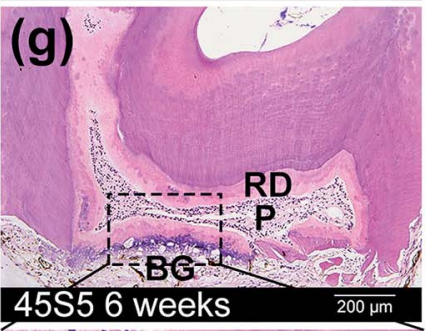

(h)
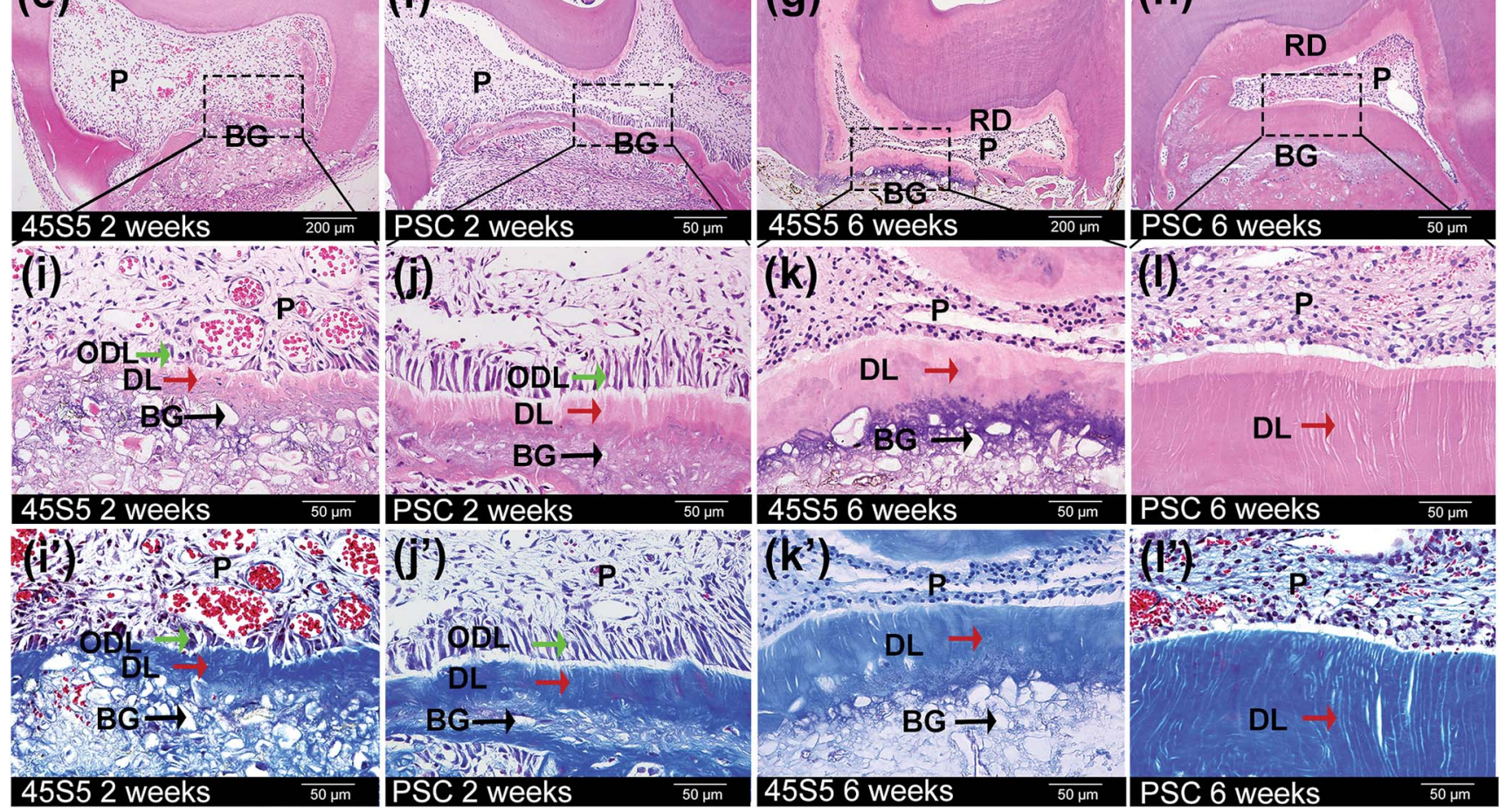

Fig. 8 PSC promoted dentin formation of DPCs in vivo. (a and b) HE staining assay showed crowns implanted alone for 2 weeks ((b) is a magnified image of (a)) and 6 weeks (c and d); (e and i) HE and (i') Masson staining assay showed crowns covered with 45S5 for 2 and 6 weeks ( $g$, k and $k^{\prime}$ ), and $\left(f, j\right.$ and $\left.j^{\prime}\right)$ crowns covered with PSC for 2 and 6 weeks ( $h, l$ and $\left.l^{\prime}\right)$. The red arrow points to the newly generated dentin like tissue; the green arrow points to the odontoblastic like cells and the black one points out the BG particles. D, dentin; BG, bioactive glass; P, pulp tissue; ODL, odontoblast-like cells; $\mathrm{DL}$, dentin-like tissue; $\mathrm{RD}$, reactive-dentin. 
dentin-pulp complex to 45S5. PSC could be used as a new potential bioactive material for the reparation and regeneration of the dentin-pulp complex.

The biocompatibility of PSC for dental pulp cells and dental pulp tissue was enhanced. PSC was derived from phytic acid as a phosphorus precursor and was characterised by several new features. PSC provided a micro-environment with a stable $\mathrm{pH}$ for cell survival and did not cause severe inflammatory responses of pulp tissues. Cultured cells are susceptible to changes in $\mathrm{pH}$, and they survive at $\mathrm{pH}$ between 6.6 and 7.8. ${ }^{20}$ Intracellular $\mathrm{pH}$ beyond this range causes growth arrest or cell death of DPCs. ${ }^{20,21}$ However, intracellular $\mathrm{pH}$ increases to 7.8 and thus serves as a permissive or obligatory signal to promote ALP activity and calcified nodule formation of DPCs. ${ }^{20,21}$ According to our data for cell proliferation and differentiation of hDPCs, the pH at approximately 7.8 (7.63-7.98) in the PSC group was more suitable for cell survival and odontogenic differentiation than that in the 45S5 group (7.66-8.84). The in vivo transplantation results were also consistent with those in the cultured hDPCs in vitro. Previous studies showed that 45S5 as a pulpotomy agent causes an acute inflammation phase and pulp tissue necrosis..$^{10}$ In our study, the transplantation results showed that pulp tissue necrosis in the PSC group (3/14) was lower than that in the 45S5 group (6/14) (Table 2). Therefore, the biocompatibility of PSC for dental pulp tissue was more efficient than that of 45S5. This observation could occur because PSC provided more stable or less fluctuated $\mathrm{pH}$ in the microenvironment for dental pulp than 45S5 did. The phosphate concentration in the PSC solution (31.59 \pm 3.76$)$ was higher than that in the $45 \mathrm{~S} 5$ solution $(27.78 \pm 2.66)$. This finding might cause slight fluctuations in the $\mathrm{pH}$ of the PSC solution because the phosphate phase in BGs are mainly orthophosphate $\left(\mathrm{PO}_{4}{ }^{3-}\right)$; a high $\mathrm{PO}_{4}{ }^{3-}$ content in BGs corresponds to a high buffering ability of BGs. ${ }^{22}$ Therefore, the biocompatibility of PSC was greater than that of $45 \mathrm{~S} 5$ because the former provided a more suitable $\mathrm{pH}$ in the microenvironment for dental pulp tissues than the latter did.

Higher Si and P concentrations released from PSC contributed to the more effective stimulation of the odontogenic differentiation of hDPCs and the formation of HCA layer than those released from 45S5. The rate of ionic dissolution and the HCA formation of BGs are important evidence of BG bioactivity. ${ }^{23}$ Ionic dissolution products from BGs promote the cell proliferation and differentiation of osteoblastic cells and DPCs. ${ }^{2,7,24}$ Furthermore, $15-30 \mathrm{ppm} \mathrm{Si}$ and $60-90 \mathrm{ppm} \mathrm{Ca}$ induce osteostimulation, ${ }^{25-27}$ but favourable ion concentrations for the odontogenic differentiation of DPCs remain unclear. In this study, the ion concentrations for the odontogenic differentiation of DPCs were 13.96-19.04 ppm Si, 73.16-74.22 ppm Ca and 27.78-31.59 ppm P. The amounts of Si and P (19.43 ppm Si, $31.59 \mathrm{ppm}$ P) released by PSC were larger than those released by $45 \mathrm{~S} 5$ in the dissolution. The rate of ion release is largely dependent on the specific surface area of BG particles. ${ }^{28}$ More ions were released by PSC than by $45 \mathrm{~S} 5$ possibly because the surface area of PSC was 45 times greater than that of $45 \mathrm{~S} 5$. High $\mathrm{Si}$ and $\mathrm{P}$ concentrations in the appropriate concentration range are more effective for cell proliferation and odontogenic differentiation of hDPCs.,7 The apatite-forming ability of PSC was also stronger than that of $45 \mathrm{~S} 5(12 \mathrm{~h} v s .72 \mathrm{~h})$ possibly because $\mathrm{Ca}^{2+}$ in PSC is mainly located near the phosphate tetrahedron, which resembles calcium phosphates in physiological media, ${ }^{13}$ although the $\mathrm{Ca}^{2+}$ concentration in the PSC dissolution was not higher than that in the 45S5 dissolution. PSC with a higher HCA formation ability than 45S5 was also likely more suitable for bonding to hard and soft tissues of dentin-pulp complex because HCA layer is essential for the rapid bonding of BGs to bone and soft tissues.

Molecular events also confirmed that the odontogenic differentiation and dentin formation of dental pulp cells could be promoted to a greater extent by PSC than by 4555 because of the improved bioactivity of the former. Although the ionic dissolutions of PSC and 45S5 upregulated the mRNA expression levels of $D S P P, D M P-1$ and $O C N$, the mRNA expression levels of $D S P P$ and $D M P-1$ on day 3 and the expression levels of the three genes on day 7 were more upregulated by PSC than by 45S5. These investigated genes were identified as specific markers of the odontogenic differentiation of hDPCs in previous studies. $^{29-31}$ The generated proteins from DSPP and DMP-1 are special non-collagenous proteins in dentin and possibly responsible for the initiation and modulation of dentin mineralisation. ${ }^{30,32,33}$ The difference in the upregulation of these gene expressions in hDPCs by PSC and $45 \mathrm{~S} 5$ resulted in variations in the generation of mineralised nodules of hDPCs in vitro and dentin formation in vivo in our study.

The regeneration of dentin-pulp complex-like tissue with odontoblast-like cells, predentin and tubule-dentin-like tissues promoted by PSC was more efficient than that induced by $45 \mathrm{~S} 5$. To confirm the interaction between BGs and dental pulp tissues, we produced tooth crown models of dentin-pulp complex regeneration in vivo. ${ }^{7}$ When the whole section-face is covered, BGs can interact with pre-existing odontoblasts and underlying dental pulp cells. In the absence of infection, the pre-existing odontoblasts in all of the groups survived and their reactionary responses were detected at the pulp-dentin interface. The reparative responses were found in the PSC and 45S5 groups but not in the control group. DPCs were stimulated by PSC to differentiate into polarising odontoblast-like cells and the secretion of the generated cells was promoted to regenerate a continuous layer of dentin-like tissue with well-organised dentinal tubules.

These phenomena were more remarkable in the presence of PSC than in the presence of 45S5, although 45S5 performed a similar function. However, dentin generated by $45 \mathrm{~S} 5$ was less regular and thinner than that produced by PSC. The typical features of the reactionary/reparative responses of the dentinpulp complex include the generation of the classical structure of odontoblasts and tubular dentin tissues. ${ }^{34}$ For instance, odontoblasts are columnar and polarisable cells are arranged along the border of the mineralisation front in the dentin-pulp interface, while one long cytoplasmic-attached extension remains behind and embedded in dentinal tubules in the calcified matrix..$^{35}$ This typical pulp-dentin complex structure is a unique characteristic of dentin and thus differentiates this part from other hard tissues. ${ }^{36}$ The typical pulp-dentin complex 
structure could also be observed in the interaction between bioactive glasses and dental pulp tissues for the reparation and regeneration of the dentin-pulp complex in the PSC group. For tissue regeneration, the degradation speed of the biomaterial with the generation of new tissues is an important factor. ${ }^{37}$ Nevertheless, the degradation ability of PSC should be further investigated.

\section{Conclusion}

In conclusion, the biocompatibility and bioactivity of PSC were more remarkable than those of 45S5. The induction of odontogenic differentiation and dentin formation of DPCs facilitated by PSC were more efficient than those stimulated by 45S5. This novel PSC bioactive glass might be a potential candidate for dentin-pulp complex regeneration.

\section{Acknowledgements}

This study was supported by the National Natural Science Foundation of China (No. 51372005). The authors deny any conflicts of interest related to this study. We appreciate Prof. Xiao-Feng Cheng from the South China University of Technology for the experimental 45S5 materials.

\section{References}

1 L. L. Hench, J. Mater. Sci.: Mater. Med., 2006, 17, 967-978.

2 W. Gong, Z. Huang, Y. Dong, Y. Gan, S. Li, X. Gao and X. Chen, J. Endod., 2014, 40, 83-88.

3 T. Qu and X. Liu, J. Mater. Chem. B, 2013, 1, 4764-4772.

4 G. H. Kim, Y. D. Park, S. Y. Lee, A. El-Fiqi, J. J. Kim, E. J. Lee,

H. W. Kim and E. C. Kim, J. Biomater. Appl., 2015, 29, 854-866.

5 W. J. Bae, K. S. Min, J. J. Kim, H. W. Kim and E. C. Kim, Dent. Mater., 2012, 28, 1271-1279.

6 S. Wang, Q. Hu, X. Gao and Y. Dong, J. Endod., 2016, 42, 1070-1075.

7 S. Wang, X. Gao, W. Gong, Z. Zhang, X. Chen and Y. Dong, Acta Biomater., 2014, 10, 2792-2803.

8 B. Oguntebi, A. Clark and J. Wilson, J. Dent. Res., 1993, 72, 484-489.

9 B. R. Oguntebi, T. Heaven, A. E. Clark and F. E. Pink, J. Endod., 1995, 21, 79-82.

10 N. Salako, B. Joseph, P. Ritwik, J. Salonen, P. John and T. A. Junaid, Dent. Traumatol., 2003, 19, 314-320.

11 E. A. Abou Neel, D. M. Pickup, S. P. Valappil, R. J. Newport and J. C. Knowles, J. Mater. Chem., 2009, 19, 690-701.

12 A. L. Li and D. Qiu, J. Mater. Sci.: Mater. Med., 2011, 22, 26852691.

13 A. Li, D. Wang, J. Xiang, R. J. Newport, M. X. Reinholdt, P. H. Mutin, D. Vantelon, C. Bonhomme, M. E. Smith,
D. Laurencin and D. Qiu, J. Non-Cryst. Solids, 2011, 357, 3548-3555.

14 R. L. Siqueira and E. D. Zanotto, J. Mater. Sci.: Mater. Med., 2013, 24, 365-379.

15 T. Kokubo and H. Takadama, Biomaterials, 2006, 27, 29072915.

16 S. Gronthos, M. Mankani, J. Brahim, P. G. Robey and S. Shi, Proc. Natl. Acad. Sci. U. S. A., 2000, 97, 13625-13630.

17 T. D. Jones, H. Naimipour, S. Sun, M. Cho and S. B. Alapati, J. Endod., 2015, 41, 50-55.

18 S. Liu, S. Wang and Y. Dong, J. Endod., 2015, 41, 652-657. 19 Y. Lu, T. Liu, H. Li and G. Pi, Int. Endod. J., 2008, 41, 643-650. 20 T. Okabe, M. Sakamoto, H. Takeuchi and K. Matsushima, J. Endod., 2006, 32, 198-201.

21 Y. Hirose, M. Yamaguchi, S. Kawabata, M. Murakami, M. Nakashima, M. Gotoh and T. Yamamoto, J. Endod., 2016, 42, 735-741.

22 M. D. O'Donnell, S. J. Watts, R. V. Law and R. G. Hill, J. NonCryst. Solids, 2008, 354, 3561-3566.

23 J. R. Jones, Acta Biomater., 2015, 23, S53-S82.

24 A. Hoppe, N. S. Guldal and A. R. Boccaccini, Biomaterials, 2011, 32, 2757-2774.

25 L. L. Hench, J. Eur. Ceram. Soc., 2009, 29, 1257-1265.

26 P. Valerio, M. M. Pereira, A. M. Goes and M. F. Leite, Biomaterials, 2004, 25, 2941-2948.

27 I. Christodoulou, L. D. Buttery, P. Saravanapavan, G. Tai, L. L. Hench and J. M. Polak, J. Biomed. Mater. Res., Part B, 2005, 74, 529-537.

28 P. Sepulveda, J. R. Jones and L. L. Hench, J. Biomed. Mater. Res., 2001, 58, 734-740.

29 K. Narayanan, R. Srinivas, A. Ramachandran, J. Hao, B. Quinn and A. George, Proc. Natl. Acad. Sci. U. S. A., 2001, 98, 4516-4521.

30 W. T. Butler and H. Ritchie, Int. J. Dev. Biol., 1995, 39, 169179.

31 M. Morinobu, M. Ishijima, S. R. Rittling, K. Tsuji, H. Yamamoto, A. Nifuji, D. T. Denhardt and M. Noda, J. Bone Miner. Res., 2003, 18, 1706-1715.

32 M. Prasad, W. T. Butler and C. Qin, Connect. Tissue Res., 2010, 51, 404-417.

33 W. T. Butler, Operative dentistry, 1992, 5, 18-23.

34 J. L. Ferracane, P. R. Cooper and A. J. Smith, Odontology, 2010, 98, 2-14.

35 T. Sasaki and P. R. Garant, Anat. Rec., 1996, 245, 235-249.

36 A. J. Smith, N. Cassidy, H. Perry, C. Begue-Kirn, J. V. Ruch and H. Lesot, Int. J. Dev. Biol., 1995, 39, 273-280.

37 Z. Yuan, H. Nie, S. Wang, C. H. Lee, A. Li, S. Y. Fu, H. Zhou, L. Chen and J. J. Mao, Tissue Eng., Part B, 2011, 17, 373-388. 